\title{
POLÍTICAS SOCIAIS E EDUCACIONAIS: UMA DUALIDADE ENTRE CIDADANIA E FILANTROPIA
}

\author{
SOCIAL AND EDUCATIONAL POLICIES: A DUALITY BETWEEN \\ CITIZENSHIP AND PHILANTHROPY
}

\section{POLÍTICAS SOCIALES Y EDUCATIVAS: UNA DUALIDAD ENTRE CIUDADANÍA Y FILANTROPÍA}

\author{
Viviane Spadaro Di Gesu' \\ viviane.spadaro@cruzeirodosul.edu.br \\ Dirce Harue Ueno Koga² \\ dhkoga@pucsp.br \\ Roberto Gimenez \\ roberto.gimenez@unicid.edu.br
}

\section{RESUMO}

O presente artigo apresenta uma discussão sobre a relação da cidadania versus filantropia no campo da proteção social brasileirae da educação. Analisou-se esta trajetória tendo como cenário as práticas socioassistenciais educacionais na perspectiva do Estado, do sentido público no provimento dos serviços e da afirmação dos direitos sociais e educacionais neste campo. A partir do resgate sociohistórico que identifica a dinâmica em curso na sociedade brasileira, o artigo apresenta o tratamento dado à questão social no país, o qual se pautou mais no campo da proteção próxima e da responsabilidade individual e privada, e o tratamento da educação que se aproximou mais efetivamente no espaço privado e elitizado.

PALAVRAS-CHAVE: FILANTROPIA; CIDADANIA; ASSISTENNCIA SOCIAL; EDUCAÇÃO.

\section{ABSTRACT}

This article presents a discussion on the relationship between citizenship versus philanthropy in the field of Brazilian social protection and education. This trajectory was analyzed taking as a backdrop the educational socio-assistance practices from the perspective of the State, the public sense in the provision of services and the affirmation of social and educational rights in this field. Based on the socio-historical rescue that identifies the dynamics underway in Brazilian society, the article presents the treatment given to the social issue in the country, which was guided more in the field of close protection and individual and private responsibility, and the treatment of

\footnotetext{
1 Universidade Cruzeiro do Sul

2 Pontifícia Universidade Católica de São Paulo

3 Universidade Cidade de São Paulo.
} 
education that approached more effectively in the private and elite space.

\section{KEY WORDS: PHILANTHROPY; CITIZENSHIP; SOCIAL ASSISTANCE; EDUCATION.}

\section{RESUMEN}

Este artículo presenta una discusión sobre la relación entre ciudadanía versus filantropía en el campo de la protección social y la educación brasileñas. Esta trayectoria se analizó en el contexto de las prácticas educativas de asistencia social desde la perspectiva del Estado, el sentido público en la prestación de servicios y la afirmación de los derechos sociales y educativos en este campo. Basado en el rescate sociohistórico que identifica la dinámica en curso en la sociedad brasileña, el artículo presenta el tratamiento dado a la cuestión social en el país, que se guió más en el campo de la protección cercana y la responsabilidad individual y privada, y el tratamiento de la educación que se acercó más efectivamente en el espacio privado y elitista.

\section{PALABRAS CLAVE: FILANTROPÍA; CIUDADANÍA; ASISTENCIA SOCIAL; EDUCACION}

\section{INTRODUÇÃO}

Esse artigo é resultado de uma dissertação de mestrado que trata sobre o processo sociohistórico de práticas socioassistenciais desenvolvidas pelas igrejas protestantes no Brasil, enquanto práticas que perpassam o tensionamento entre a cidadania e a filantropia, na medida em que se aproxima, se distancia ou se desloca em relação a atuação do Estado, especialmente, no que se refere à política de assistência social, com uma história recente de reconhecimento enquanto política pública. Além disso, o artigo adentra a temática do direito à educação, que também, de forma desafiadora, se desenvolveu sob um percurso turbulento no espaço brasileiro.

Dessa forma, apresenta-se a atuação das igrejas protestantes no Brasil enquanto parte do universo do terceiro setor, que tem sua trajetória sociohistórica marcada pelo papel da igreja católica, assumindo um protagonismo no campo socioassistencial anterior ao próprio Estado.

Tal discussão se faz necessária uma vez que o Estado, não assumindo seu papel de provedor de direitos aos indivíduos, abriu espaço para que as organizações sobretudo de origem religiosa o fizessem, mediante o contexto de desigualdade, vulnerabilidade e urgência em que tais pessoas se encontravam.

Dessa forma, inicialmente, apresenta-se uma contextualização do objeto e do problema em questão, adentrando a temática filantropia $X$ cidadania, a partir do 
resgate sócio histórico que identificam a dinâmica em curso na sociedade brasileira entre essas duas perspectivas, as quais perpassam o debate do sentido público das políticas sociais, tendo como foco a política de assistência social, que tem suas raízes fincadas nas relações de benemerência e favor marcadas pela meritocracia individual. Nesta perspectiva, a pobreza e a indigência, assim como a doença são naturalizadas e identificadas como de responsabilidade dos indivíduos e não como expressões da questão social, intrínseca ao modo capitalista de produção e reprodução de desigualdades sociais. O tema educação transpassa tal temática uma vez que também recebeu influências e consequências de uma conjuntura social, política e econômica capitalista perversa.

O tema da questão social teve como referência o trabalho desenvolvido por Robert Castel (Metamorfoses da Questão Social - 1998), que, embora privilegie a sociedade francesa como foco de suas reflexões, traz importantes aportes que, podem ser relacionados aos dos contextos sociohistórico e econômico do Brasil, sob o ponto de vista do processo de construção do sistema protetivo que se pautou mais no campo da proteção próxima (no seio familiar e comunitário) e da responsabilidade individual e privada.

A história da filantropia foi desenvolvida a partir de Mestriner (2005), a qual pode ser entendida como sendo inicialmente da forma caritativa, do Período Imperial até 1889 , evoluindo para a forma higiênica de 1889 até 1930 , se caracterizando como disciplinadora de 1930 até 1945, partilhada de 1946 até 1964, de clientela de 1964 até 1988, vigiada de 1985 até 1988 e por fim democratizada de 1988 até 1999.

\section{UM OLHAR SOBRE O ENFRENTAMENTO DA QUESTÃO SOCIAL: ENTRE AFILANTROPIA E A CIDADANIA}

Na trajetória da proteção social brasileira, observou-se a marca da perspectiva filantrópica no seu enfrentamento às expressões da questão social. Ao longo dos séculos, experimentou-se a proteção social sob diferentes versões, que se traduziram, no interior de vários países, em formas distantes do campo dos direitos e da cidadania. A cidadania, segundo a conceituação sociológica clássica de Marshall (1967):

Pode ser considerada a partir de três subdivisões de direitos: o civil, o político e o social. Cidadão incompleto corresponderia àquele para quem algum desses direitos estava suprimido, enquanto o não cidadão se referiria ao indivíduo que não desfrutasse de nenhum dos três direitos.(MARSHALL, 1967, p. 63)

Ao resgatar a trajetória protetiva na sociedade feudal europeia, observa-se que a chamada proteção próxima traduzia-se na única garantia de assistência social aos indivíduos pobres das comunidades, já que esses não poderiam valer-se de 
qualquer forma de cidadania. Essa versão de proteção estava vinculada ao processo de pertencimento familiar, de pertencimento à comunidade ou de participação das relações de trabalho. A proteção próxima, nessas sociedades pré-industriais, se dava sob a lógica do socorro, ou seja, no momento da carência, relativa ao suprimento das necessidades imediatas mais elementares. Era comum, no século VIII, durante o feudalismo, homens livres servirem um senhor feudal em troca de proteção, evitando assim, a miséria. Em contrapartida, no que tange à educação, na idade média, a igreja dominava as escolas, uma vez que os monges eram os únicos letrados na época. Os indivíduos que acessavam a educação faziam parte das camadas privilegiadas da sociedade.

A ausência das relações de sangue, de nacionalidade ou de vínculo de trabalho, que na Idade Média asseguravam a proteção, traduzia a completa desproteção social para os indivíduos pobres. Segundo Castel (1998), esse cenário de desproteção se configurava como uma desfiliação: que significaria, num primeiro sentido, uma ruptura desse tipo de relação às redes de integração primárias. Para esse grupo de rejeitados indesejáveis, que não passavam de pesos mortos para a sociedade, por se encontrarem na condição de total dependência, restava a acolhida benemérita da comunidade próxima, que era obrigada a suportá-los, já que não havia alternativa para solucionar o problema, pois tal fato não era reconhecido como uma questão social, antes, era visto como sinal de perigo ou doença social, já que poderia causar a desarmonia social, caso não fosse contornado.

A sociabilidade secundária, formada por organizações especializadas no atendimento socioassistencial, sobretudo instituições como hospitais e orfanatos, rapidamente se fez necessária para socorrer os miseráveis, fragilizados pela perda da sociabilidade primária. Essa foi a primeira demonstração na história da organização social por si mesma, isto é, a primeira vez que houve iniciativa por parte da sociedade civil diante das demandas de proteção social. Portanto, essa foi a versão primitiva de assistência social instalada no período medieval analisado por Castel (1998) no contexto francês.

Dentre os que tinham a função de exercer a sociabilidade secundária aos empobrecidos, estavam os religiosos, já que esses eram vistos como aqueles que deveriam servir a Deus e aos pobres. A prática da caridade, do dar esmolas, do ato de doação, no período medieval, associada à salvação, ao perdão dos pecados, era frequente, em especial entre a classe social privilegiada. Da mesma forma, sob o palco da educação, as instituições religiosas detinham o privilégio do poder do conhecimento. Cumpre destacar que a concentração de riqueza e o monopólio das informações constituíram-se pilares importantes para a manutenção do status das entidades religiosas durante o regime feudal (PACE, 2007). 
Além disso, foi neste período que muitas instituições religiosas se envolveram no trabalho associado a idosos, crianças abandonadas, bem como, pessoas com deficiência. Para REILY (2007), por exemplo, o início dos trabalhos associados à Língua de Sinais teria acontecido ainda no período medieval.

Desse modo, os religiosos eram participantes do grupo dos que se dedicavam ao campo social, juntamente com os profissionais da saúde e do ensino. Assim, as igrejas e os conventos, exercendo seu poder político e de legitimidade, compunham o grupo das organizações que amparavam os pobres, com a peculiaridade de rapidamente se tornarem as instituições com maior volume de práticas de dedicação assistencial, durante as décadas subsequentes. Os pobres não pertencentes à comunidade e os vagabundos, sendo vistos como perigosos, eram tratados como caso de polícia.

As primeiras movimentações efetivas de governos, no campo social, passaram então a existir no século XVI, a partir das elaborações e reelaborações de políticas municipais, dentre as quais se definiam a necessidade de ensinar um trabalho às crianças, direcionar os pobres doentes a um tratamento e distribuir auxílios aos que a renda familiar não se fazia suficiente. A partir de então, a assistência social e a educação começam a se estender a um maior número de pessoas. Tem-se assim a afirmação de uma pioneira, mas já perversa lógica de tratamento social: a ação mínima, por parte do Estado, aos mais pobres dos pobres capazes de acessar o sistema de proteção ofertado.

Os hospitais foram as organizações sociais que passaram a acolher os então desfiliados idosos ou doentes ou ainda abandonados, isto é, os mais miseráveis dentre os mais pobres. Albergues passaram a aceitar e assentar indigentes capacitados ao trabalho (capturados), para servirem e trabalharem como escravos, quando necessário, sob a forma de trabalho forçado. Os mosteiros e as paróquias eram campo de ensino para as crianças que tinham acesso ao letramento, quando as mesmas não eram educadas em casa:

Há pouca diferença na Idade Média na educação dada às crianças de diversas condições; os filhos dos vassalos menores são educados na residência senhorial juntamente com os do suserano, os dos ricos burgueses são submetidos à mesma aprendizagem que o último dos artesãos, se querem tomar conta, por sua vez, da loja paterna.(PERRENOUD, 1997, p. 97)

Com o fim do feudalismo e o início da sociedade capitalista, a condição de assalariado, nascia sob uma posição degradante: era destinada aos pobres arruinados que tudo o que podiam fazer para reagir no mundo e ao mundo era vender o seu tempo e alugar a força de seus braços a alguém. A partir de então, havia duas opções ao trabalhador: trabalhar de forma forçada e imposta (tratamento da vagabundagem) ou 
trabalhar sob as regras dos ofícios e do operariado. Ser cidadão e incluído significava fazer parte do corporativismo hierárquico.

No âmbito da Educação, a pretensão das monarquias europeias na busca de atender às necessidades da expansão das navegações foi determinante para o investimento no estabelecimento de instituições voltadas para o aprimoramento técnico e posteriormente científico (PASQUALOTTO, 2006). Em parte, este movimento teria resultado posteriormente no cultivo de uma massa crítica que passou a ter condições de questionar doenças, contribuir para a evolução de máquinas, equipamentos e transporte, subsídios fundamentais para o modelo capitalista.

Foi somente com a Revolução Industrial e com a modernidade liberal que a condição de assalariado deixa de ser do tipo tutelar para ganhar liberdade e passar a ser na forma de contrato. A situação instalada no século XVIII demonstrava a existência de uma vulnerabilidade coletiva, uma pobreza estrutural que compreendia milhares de pessoas incapazes de se alimentar, vestir e habitar por si mesmas. Essa constatação trazia a consciência (falsa) de que o trabalho era a fonte de riquezas. O século XVIII, marcado pelo movimento iluminista, teve grande repercussão no campo educacional. A partir das concepções teóricas dos filósofos iluministas Jean Jacques Rousseau (1712-1778) e Immanuel Kant (1724-1804), o século das luzes foi identificado como o palco das tendências liberais para a educação. Foi a partir de então que se começou a questionar a liberdade na educação, a qual deveria caminhar sem as amarras religiosas. Santos (2013 p. 7) lembra que, segundo Kant, "o homem se educa pelo desenvolvimento próprio e ativo da consciência, propondo a si mesmo seus ideais (autonomia) e reconhecendo o direito dos demais indivíduos de também cultivar-se livremente".

A partir da Revolução Industrial do século XVIII, passou-se a valorizar o individualismo. A caridade, o socorro, a filantropia e a repressão deixaram de ser temas do novo discurso sobre os inválidos, embora a assistência social, que deveria ser oferecida e sustentada pelo Estado (providência), era ainda somente aos domiciliados incapacitados ao trabalho (conservando assim seu caráter restritivo). $O$ socorro aos beneficiários de tal assistência social mal atendia as necessidades básicas dos miseráveis, mas já era visto pelos dominadores como um direito ao cidadão, um mérito, um avanço no que se refere ao tratamento da questão social.

Todas as ações do Antigo Regime tais como políticas de combate à mendicância, vagabundagem e os sistemas de socorro (hospitais, asilos, esmolaria, taxas de caridade, renda mínima) não evitaram, nem de longe, o problema do agravamento da pobreza. O Novo Regime sob a lógica liberal, só contribuiu para agudizar ainda mais essa situação. Sob o contexto da modernidade, ficou cada vez mais claro que pobre não é aquele que não trabalha, mas é aquele que trabalha de 
forma assalariada. Mudou-se a situação, porém, permaneceu a condição indigna e insegura, na vida dos trabalhadores.

Segundo Castel (1998), sociedades morais cristãs ou sociedade de socorros mútuos, criadas a partir de 1828, compostas por voluntários protestantes, católicos, banqueiros e industriais se dispunham a procurar uma solução à fratura social que estava se agravando ainda mais. Usando da filantropia para recuperar pessoas e combater a pobreza, tentavam prevenir e evitar a desordem social.

Para mudar o amparo social e aprimorar o controle dos mais pobres, no início do século XIX, foi proposto o embrião do que mais tarde seria conhecido como seguridade social, isto é, o incentivo a poupanças e previdência (caixas de aposentadoria) em caixas econômicas.

Havia, nesse contexto, uma proteção oferecida pelo governo (a mais minimalista), a provinda da sociedade civil e uma terceira, provinda dos patrões, que para manter sua mão de obra, ajudavam seus operários empobrecidos.

No século XIX, na França, observa-se que todas as leis e decretos promulgados nunca eram a favor dos interesses e necessidades dos desafortunados, mas se configuravam como uma solidariedade movida por segundos interesses (troca), como a manutenção da ordem, o afastamento da vergonha nacional causada pelos miseráveis, a legitimação do Estado, a reabilitação ao trabalho.

Pela primeira vez na história europeia, os poucos que conseguiram receber sua aposentadoria, aos 65 anos (por não terem morrido antes) continuaram na pobreza, pois essa era pouco maior que os subsídios dados aos indigentes. Viuse mais uma frustração no sonho de melhoria de vida. Conservava-se assim uma classe não proprietária, sem parte na distribuição das riquezas, mas confortada por saber que não sucumbiria. Isso se configurava como uma estratégia de contenção reivindicatória.

O Estado passou a exercer o papel de gestor da seguridade, a qual poderia ser acessada mediante a condição de invalidez por doença, acidente ou velhice do trabalhador. Embora assumindo a forma clientelista de tratamento da pobreza, o problema da desfiliação parecia estar sob controle, sem tutela, sem dependência, sem necessidade de vínculo territorial, graças ao seguro social do século XX.

Seguindo os interesses do mercado, tornou-se importante que essa massa trabalhadora, também pudesse consumir os produtos do trabalho, devolvendo parte de sua remuneração, obtida na forma de salário, aos donos das fábricas. Inicia-se a preocupação com o bem-estar, conquistado por meio do consumo. Porém, para tal consumo acontecer, minimamente, o salário deveria ser mais elevado, o que seria possível se o trabalhador trabalhasse ainda mais. Aqueles que obtinham salários melhores, certamente eram os que conseguiam melhor se beneficiar dessa nova 
lógica social. Muitos, que nem as condições de operário possuíam, continuavam vivendo a limitação dos acessos e consequentemente a frustração de seus sonhos. Segundo Dantas (2003),

O projeto taylorista, ao qual Henry Ford e sua linha de montagem móvel dariam contornos maiores e definitivos, tinha, consciente e declaradamente, um amplo alcance social: visava incorporar aos padrões capitalistas de produção e consumo, uma enorme massa de milhões de pessoas que viviam à margem daqueles padrões, mas desejavam a eles aderir ("fazer a América"). As invenções de Eastman, Edison, Westinghouse, tantos outros, bem como os novos processos de produção introduzidos por Taylor, Fayol, Ford e seus contemporâneos, criavam um mercado capitalista para consumo de capital, neste mercado incorporando, tanto na ponta da produção quanto na do consumo, um novo tipo de trabalhador fabril, homogeneizado e massificado. O consumo das classes trabalhadoras ("colarinhos brancos" ou "azuis") começava a incorporar novos ítens que pouco teriam a ver com subsistência, como assim o entenderia Marx, mas muito estavam relacionados às exigências da acumulação: para continuar crescendo, o capital inventava produtos e novas indústrias, nisto necessitando também inventar, via publicidade, os seus respectivos consumidores. (DANTAS, 2003, p. 13-14)

Quando se instalou o direito às férias remuneradas, em 1936, o repouso semanal e a redução de jornada de trabalho, configurou-se o desespero dos patrões, agora temerosos dos avanços da classe operária. Abria-se a era da humanidade, com o reconhecimento da natureza sentimental e emocional do homem, que não se resumia a uma máquina de trabalho, mas possuía vida pessoal, necessidade de descanso, direito de ter algum tempo para si mesmo e para fazer suas próprias escolhas. O movimento operário ganhava fora lutando por novas conquistas. Temiase revoluções, reformas, tomada de poder e luta de classes.

A partir de 1975 (portanto, após a crise do Fordismo ocorrida na década de 60 ), sob o contexto europeu, o número de trabalhadores operários passou a diminuir e os empregados assalariados não-operários, começaram a aumentar. Esses sem executar trabalhos mecanicamente manuais, ganhavam mais e por isso sua posição social passou a ser mais interessante. Eram os assalariados burgueses do setor terciário. Conforme nos lembra Dantas (2003), no final dos anos 1970 o mundo vivia a terceira revolução industrial em que as organizações dependiam mais de equipamentos automatizados digitais.

As organizações comerciais e financeiras empregavam enormes e cada vez menos produtivas massas de trabalhadores de escritório, no tratamento e comunicação de informação, necessitando de equipamentos capazes de automatizar essas atividades". (DANTAS, 2003, p. 18)

Como consequência das exigências da globalização, a hierarquia salarial se estendeu, a qualificação dos trabalhadores aumentou, a própria função do operário se diversificou e as atividades profissionais se expandiram. Configurava-se uma nova 
classe de trabalhadores, a classe média, conquistando melhoria de vida. Conforme Castel (1998), as diferenças salariais reafirmaram a existência de uma sociedade de disparidades sociais. Com tais sentimentos de conquista, houve um enfraquecimento na politização e na contestação social por parte dos trabalhadores. Diante desse contexto, a burguesia propôs a inadiável institucionalização da escola pública. Tratavase de uma decisão política em defesa da classe dominante e manutenção da ordem, direcionando os proletários ao trabalho, à obediência.

A classe dominante procurou historicamente incutir no processo formativo do indivíduo, por meio da escola pública, da educação técnica e geral e da liberdade religiosa, os valores determinantes para construção do homem moderno, ou seja, os valores da sociedade do capital que visam garantir a ordem social capitalista. Haja visto que, quando da institucionalização de uma escola pública que possibilitaria a formação do homem como um ser histórico e total, a burguesia evitou que esse homem moderno fosse educado para reconhecer a luta de classes, para "ver" a sua essência e sua real condição social, conhecimentos que poderiam levá-lo a se levantar contra a exploração, as injustiças, a manipulação alienada e a superação da sociedade capitalista. (SOUZA, FERREIRA e BARROS, 2009, p.497)

Tem-se um novo homem, inteligente, empreendedor, autônomo, espalhado nas mais variadas profissões estatais ou privadas, não necessariamente dependentes de um patrimônio para ter acesso a uma condição mais favorecida, mas que agora era possível de obter, com o auxílio dos créditos. O diploma poderia indicar o acesso aos bens duráveis, em contrapartida, o número de trabalhadores do setor primário, com baixa qualificação, passava a ser reduzido.

Após a Segunda Guerra Mundial (1945), na era pós liberal, o Estado Social interveio na economia europeia, regulamentando-a e nacionalizando organizações, fazendo valer os ideais keynesianos ao prover o social com serviços públicos e propriedades sociais, que cada um tinha em parte e por inteiro, sem apropriação: era o WelfareState, nunca vivenciado no Brasil.

É importante lembrar que Bismarck, chanceler alemão, com suas políticas sociais, criou o seguro social bismarckiano, o qual se propôs a promover o Estado de Bem-Estar Social, protegendo os trabalhadores contra acidentes de trabalho e invalidez, além de prover amparo em caso de doenças e velhice. Na Inglaterra, a seguridade social foi possível a partir do modelo de Beveridge, que se preocupava em compensar o trabalhador em caso de perda de salário (FARIA, 1998, p. 50-52).

Definiu-se então o salário mínimo mensal, agora, entendido como o pagamento não apenas de uma tarefa única, mas de um conjunto de atividades de valor cuja remuneração ia além do tempo e dos dias de atividade dentro de uma organização.

O desemprego trouxe a queda do consumo, junto com as suas consequências: cortes de custos, demissões, subempregos, ou seja, o risco da desfiliação 
renascia. Parece que a história retrocede, mas com novo título, o de flexibilidade, já que trabalhadores passaram a ser contratados (alugados) por hora ou dias para desempenhar o trabalho que fosse necessário. Expandia-se a terceirização, que representava o rebaixamento da remuneração do trabalhador e acirrava-se a competição e a exclusão, em especial, daqueles não aptos e capacitados a essa nova sociedade - a maioria dos assalariados.

Sob essa condição, os vínculos se perdem, inclusive os conjugais e familiares, instalando-se a proximidade da zona de assistência social. As famílias modernas se desestabilizam mais facilmente uma vez que nem sempre tem sua formação completa (composta de homem, mulher e filhos). Resta aos excluídos fazer parte de sociabilidades provisórias, que the permitam algum tipo de pertencimento, ainda que temporário, mas que nem sempre lhes permite sentido futuro.

\section{A POBREZA COLONIZADA NO BRASIL E A TRAJETÓRIA DA FILANTROPIA}

Respeitando-se as diferenças impostas ao Brasil, em relação à Europa, a sua regulação social se fez tardiamente (SPOSATI, 2002). Entretanto, ela ocorreria em moldes semelhantes aos vivenciados no mundo Europeu e, mais especificamente, em países como a França e a Inglaterra. Também foi tardia a regulação da educação brasileira.

O Brasil herdou dos portugueses uma sociedade dominada e sem cidadãos. Escravos servindo nas monoculturas, mulheres sendo exploradas, crianças sendo alugadas para trabalhar. No período colonial, os indivíduos pobres, sem trabalho, sem educação, que viviam abandonados pelas ruas, sem família, juntamente com os loucos, doentes e inválidos possuíam um destino certo, sob tutela da Igreja, que os enquadrava em uma espécie de programa social filantrópico caritativo. A filantropia, inicialmente caritativa, passou séculos mais tarde a ser higiênica, sendo exercida no âmbito de uma medicina social imediatista, sob um sistema de isolamento dos que não poderiam viver no seio da sociedade.

Do século XVII até o século XIX, os mais pobres eram tratados segundo a lógica da benemerência e da caridade religiosa. Tal ajuda não era, no entanto para todos, pois antes havia uma pré-seleção para que o indivíduo fosse considerado merecedor de favor. Assim, negros, pessoas com problemas mentais, portadores de doenças contagiosas, entre outros perigosos, eram recusados. Os demais poderiam ser recolhidos e abrigados, juntos, sem qualquer critério. Nesse ponto, encontramos uma semelhança em relação trajetória da proteção social europeia. O Brasil também inicia seu trabalho de ação social de forma seletiva e discriminatória, não atendendo 
a todos os que necessitavam de auxílio, antes, escolhendo os aptos ou dignos de ajuda. No que se refere a educação, o Brasil Colônia iniciou sua empreitada de ensino por meio da participação dos jesuítas e, portanto, com o protagonismo do religioso católico.

\begin{abstract}
Pode-se considerar que a primeira medida do Estado visando a prover o acesso à educação no Brasil foram os "Regimentos" de D. João III, editados em dezembro de 1548, para orientar as ações do primeiro governador geral do Brasil, Tomé de Souza, que aqui chegou em 1549, acompanhado de quatro padres e dois irmãos jesuítas chefiados por Manuel da Nóbrega. Nesse mesmo ano, os jesuítas deram início à obra educativa centrada na catequese, guiados pela orientação contida nos referidos "Regimentos", cumprindo, pois, um mandato que Ihes fora delegado pelo rei de Portugal. (SAVIANI, 2013, p. 746)
\end{abstract}

Também o exercício da caridade, no Brasil, aconteceu semelhantemente à realidade europeia. A Igreja Católica apareceu de forma ativa no cenário social brasileiro, envolvida com os primeiros trabalhos de assistência social aos pobres. Tal fato foi possível, pois até a Proclamação da República, em 1889, vigorou no Brasil um estilo de governo civil-religioso, tendo o catolicismo como religião oficial do Estado. Assim, a Igreja funcionava como pela chave de legitimação do Estado colonizador, já que representava inclusive o espaço em que se passava a vida social da época. As Igrejas Protestantes começaram também a desenvolver seus trabalhos sociais, no decorrer do século XIX, inicialmente, no campo da educação, fundando escolas.

Sem uma ação política organizada a partir do Estado em relação aos pobres, semelhante à história da assistência social europeia, a iniciativa privada no Brasil, sob a lógica da solidariedade, passou a assumir o papel assistencial de socorro aos mais pobres.

A filantropia baseada na caridade logo se mostrou insuficiente para resolver os problemas gerados pela pobreza. Assim, sob tal contexto, surgiram os filantropos higienistas, que fundiram assistência médica com a assistência social. Os missionários religiosos passaram então a praticar uma caridade cristã disciplinar, junto aos indivíduos assistidos. Conforme lembra Abreu (1985, p. 50), tratou-se de uma estratégia em que a aliança entre filantropia e medicina social possibilitou a emergência de um espaço institucional medicalizado e politizado.

Embora o sistema assistencial da época parecesse estar bem organizado, convivia, no entanto, com vários problemas, como o dos hospitais que não comportavam o grande número de pessoas que precisavam ser atendidas. Foi nesse momento que ocorreu uma reorganização dos serviços sociais prestados pelas instituições médicas, sobretudo as Santas Casas.

A Irmandade de Misericórdia, criada em 1560, foi a primeira instituição de assistência social organizada no Brasil para cuidar dos casos de infância abandonada, 
ou seja, era a instituição que recolhia os bebês deixados pelas mães nas portas das casas. Também se dedicava ao cuidado de doentes leprosos, presos, loucos e inválidos. O serviço de acolhimento dos abandonados ficou conhecido como Roda dos Enjeitados, e passou a ser apoiado pelo governo, por meio dos municípios, que passaram a participar da assistência social, juntamente com a iniciativa privada.

Existia neste período a "Roda", local onde inseriam-se se alimentos, remédios e mensagens para os reclusos conventuais. Era uma caixa cilíndrica de madeira, repartida ao meio por tábuas, que girava sobre um pino posto sobre seu eixo principal, e era encaixada dentro da parede do edifício. (MACEDO; MARTINS, 2014, p. 13).

A responsabilidade dos municípios era fornecer recursos para manutenção dos trabalhos caridosos direcionados aos miseráveis, além de inspecionar tais serviços. Assim, observa-se na trajetória da proteção social brasileira que o Estado tardiamente entrou para a cena social, provendo a iniciativa privada de auxílio na forma de recursos a serem utilizados no socorro aos pobres. Os recursos também provinham da iniciativa privada. Segundo Landim (1993, p. 14), "os fundos que sustentavam as Santas Casas e os trabalhos caritativos provinham dos beneméritos, isto é, das pessoas de bem da sociedade colonial, como os grandes Senhores". Graças à dita generosa e leal prática da filantropia de base hierárquica e patriarcal, que pode ser denominada como senhorial, essas entidades recebiam donativos, heranças e esmolas para continuidade de seus trabalhos.

Adotou-se, assim, a disciplina da medicina higiênica, que condenava antigos hábitos familiares, causadores de doenças. Segundo Abreu (1985, p. 60), a higienização da família ocorreu paralela ao desenvolvimento urbano. Determinou-se também na época, a localização das instituições como cemitérios, prisões, escolas e adestrou-se físico, moral e intelectualmente as pessoas para se evitar a mortandade consequente das antigas práticas.

Criava-se, assim, um contexto de repressão e liberdade. Na segunda metade do século XIX, criou-se o Estatuto da Tutela que se propunha a humanizar a situação do preso, que agora suportava uma nova forma de punição: aquela que detinha, vigiava, corrigia, reeducava e sujeitava o indivíduo. Além disso, o estatuto previu a psiquiatria e o hospício para o tratamento dos loucos.

Quanto às crianças, era preciso dedicar a elas cuidados não somente físicos, mas também morais. Assim, aos filhos dos ricos, tinha-se a educação e aos filhos dos pobres, a polícia, ambas formas de docilização. Esses formavam o grupo de serviços sociais definidos pela política social da época, para tratamento da população. Em relação ao ensino, tinha-se, segundo Saviani (2013, p. 948), no Brasil Império, o "ensino secundário assumido, em geral, pela iniciativa particular, especialmente 
pela Igreja. O ensino primário, novamente, ficou abandonado". Ações em direção ao ensino superior no Brasil foram motivadas pela reforma pombalina com o objetivo de formar líderes para condução do país.

No século XIX, passou-se a organizar sociedades beneficentes de auxílio mútuo e os primeiros sindicatos, que permitiram que os direitos civis dos cidadãos fossem requeridos coletivamente, sob um contexto incipiente de industrialização. Essas sociedades eram instituições de saúde, de caráter secular, como a tradicional Real e Benemérita Sociedade Portuguesa de Beneficência de São Paulo, criada em 1840 , que prestava ajuda moral e material, incluindo auxílio à procura de trabalho, em especial, para os imigrantes.

Assim, no século XIX, sob os olhos dos disciplinadores, formavam-se os cidadãos, o que, segundo Abreu (1985, p. 71), "significava a transição da tutela, ao contrato". Transição essa caracterizada pela passagem da forma de trabalho escravo ou serviçal para aquela caracterizada pelo assalariamento.

Mantendo o caráter assistencialista ou de benemerência, a filantropia, segundo Mestriner (2005), mudou de versão: de 1930 a 1945 assumiu o caráter disciplinador; de 1946 a 1964 se caracterizou como uma filantropia partilhada; de 1964 a 1985 se assemelhou a uma filantropia de clientela e de apadrinhamento; de 1985 a 1993 a filantropia passou à versão vigiada e por fim, de 1994 a 2000, a filantropia se tornou democratizada. Essas versões filantrópicas mostram que a pobreza nunca foi enfrentada sob o contexto da cidadania e, conforme afirma Telles (2001, p. 20), "como espetáculo da encenação pública, ela foi transformada em paisagem, como natural e banal, sem responsáveis, passível de compaixão privada e de ser facilmente desconversada".

A partir da década de 1930 no Brasil, até 1945, sob o governo de Getúlio Vargas, houve o que se pode chamar de Filantropia disciplinadora. Nessa época, o Estado resolveu fazer uma revolução no campo social, antes que a população o fizesse. Assim, o Estado passou a acompanhar mais de perto as obras sociais e a incentivar as organizações que ofereciam serviços sociais à população, oferecendoIhes subsídios. Esse trabalho de coordenação das beneficências particulares era feito pela Caixa de Subvenções, criada em 1931.

Em 1938, foi criado o Conselho Nacional de Serviço Social (CNSS), como a primeira regulamentação da assistência social no Brasil, a qual associava a iniciativa estatal com a privada a fim de acabar com a dependência às caridades. Em 1994, o antigo CNSS foi substituído pelo Conselho Nacional de Assistência Social (CNAS), o qual trabalhava em conjunto com o Ministério da Educação e Saúde (esse último tem por função assegurar o trabalhador em condições de empregabilidade), perpetuando o vínculo do Estado com o enraizado processo filantrópico e benemérito de assistência 
social. Na época colonial, portanto, a dependência ao socorro social era sustentada pelos Senhores, a partir da primeira metade do século XX ela passa a depender de novas figuras políticas.

Foi, portanto, Getúlio Vargas que permitiu os primeiros passos mais representativos da Área social. Ainda que, de forma prematura, tais fatos representaram grande ganho, já que se está considerando um passo marcado pelo tratamento da pobreza sob a benemerência não estatal.

Segundo Carvalho (2004, p. 83), até 1930 havia no Brasil uma "cidadania em negativo", já que os indivíduos não usufruam completamente de nenhum dos direitos. A partir de 1930, no entanto, houve avanços nos direitos sociais, em especial quanto aos ligados ao trabalho (em 1943 foi criada a CLT Consolidação das Leis do Trabalho). Os direitos políticos, por outro lado, enfrentaram maiores obstáculos devido aos regimes políticos que se instalaram no país e, conforme afirma Telles (2001, p. 22), "o modelo de cidadania corporativo instalado não constitui a figura moderna do cidadão referida a uma noção de indivíduo como sujeito moral e soberano nas suas prerrogativas políticas na sociedade".

A questão social no Brasil nasce definitiva e reconhecidamente com a industrialização e com o operariado reivindicando melhorias de trabalho. Antes desse fato, a questão social por ser desconsiderada, era tratada como caso de polícia, a fim de reprimir os que perturbavam a ordem, com sua vergonhosa pobreza.

Getúlio também criou a benemerência estatal, na figura da benemérita primeira-dama da Área social, em 1942 com a Legião Brasileira da Assistência (LBA), que incentivou a solidariedade e o voluntariado feminino, repassando, mais uma vez a responsabilidade do social para a sociedade civil, provando que a história se repete, já que tal órgão governamental tinha seus recursos provindos também de doações de particulares.

O estadista preocupado em acelerar a industrialização, pouco se dedicou a buscar erradicar as causas da pobreza, no entanto, usou o corporativismo como uma estratégia de controle dos trabalhadores, o que demonstrava o jogo do governo para manter a desigualdade e ocultar o conflito social instalado. O Ministério do Trabalho, Indústria e Comércio, criado em 1930, ao invés de se colocar em defesa do trabalhador, passou a ser um órgão que direcionava questões trabalhistas segundo os interesses do governo.

Vargas retomou a relação Estado-Igreja, no que se refere ao tratamento dos pobres, apoiando e financiando obras sociais religiosas. Assim, na década de 40, a Igreja Católica passou a auxiliar o governo na prática da disciplina, cristianizando a população a partir dos bons costumes e incentivando o comunitarismo ético anticomunista, voltado à lógica liberal defendida pelo governo. 
No que se refere a educação, a partir da década de 30 a escola pública se fazia necessária para o desenvolvimento socioeconômico do país, no entanto as amarras elitistas no campo educacional, permaneceram. Dessa forma, com a Constituição de 1934 instituiu-se o ensino primário gratuito de quatro anos. Reformas e Leis Orgânicas do Ensino foram adotas no país a durante a ditadura varguista. A Constituição de 1946 previu a Lei de Diretrizes e Bases da Educação (LDB), a primeira lei específica educacional brasileira.

Esse conjunto das Leis Orgânicas do Ensino, editadas de 1942 a 1946, estabeleceram o ensino técnico-profissional (industrial, comercial, agrícola); mantiveram o caráter elitista do ensino secundário e incorporaram um sistema paralelo oficial (Serviço Nacional de Aprendizagem Industrial (Senai) e o Serviço Nacional de Aprendizagem Comercial (Senac). (BITTAR e BITTAR, 2012, p. 159)

Getúlio Vargas consagrou a "cidadania regulada", segundo Santos (1979, p. 68), quando regulamentou as atividades de trabalho restringindo-as às questões políticas. Dessa forma, a partir da década de 1930, foram regulamentados a jornada de trabalho, o trabalho feminino e o de menores, as fábricas, a sindicalização, a previdência social, ainda que, na prática, tais regras eram pouco respeitadas e a punição aos que as infringiam, inexistente.

Consolidando as leis trabalhistas, em 1943 o governo impõe a proibição de greves. As legislações serviram para aliviar os problemas, porém sacramentando as desigualdades, mantinha a dominação dos indivíduos, em nome do desenvolvimento econômico.

Não somente as instituıções católicas atuavam nessa época, no campo social, mas também grupos religiosos, como os protestantes e espíritas também começaram a ampliar seus trabalhos sociais via instituições, prestando atendimento às crianças e adolescentes. Mais tarde, em 1943, essas instituições sociais religiosas e também as laicas ganharam o título de utilidade pública e tiveram isenção de impostos, como o imposto de renda. A questão social nessa época era tratada a partir da proteção física das pessoas, sempre com a ajuda das organizações privadas. Dessa forma, o tratamento da exclusão social (se é que se pode chamar assim) era feito de forma torpe por parte do Estado.

Praticava-se o corporativismo, o favor, o clientelismo e a solidariedade junto às massas, sob um contexto, segundo Telles $(2001$, p. 26) no qual "a pobreza vira carência, a justiça se transforma em caridade e os direitos, em ajuda a que o indivíduo tem acesso não por sua condição de cidadania, mas pela prova de que dela está excluído".

A partir de 1946, até 1964, o Brasil viveu, segundo Mestriner (2005, p. 113), a "filantropia partilhada". A Constituição de 1946 abriu espaço para participação da 
classe dos trabalhadores no campo social, os quais a partir de então tinham sua legislação regulada pela Justiça do Trabalho.

O Estado assume a responsabilidade não só da regulação do trabalho, mas também da educação. Cria-se, no governo Eurico Gaspar Dutra (1946-1951), o Serviço Social do Comércio (SESC) e o Serviço Social da Indústria (SESI) entre outros serviços estaduais e municipais, os quais, com a ajuda do empresariado, objetivavam contribuir para o bem-estar dos trabalhadores, em diversas áreas como a educativa, alimentar, recreativa e da saúde, o que confere no lugar da benemerência, um caráter educacional assistência social (dirigidas apenas aos trabalhadores formais, pois os demais continuavam sob a lógica do favor).

João Goulart (1961-1964) entrou no poder sob o sistema parlamentarista, mas logo o presidencialismo foi retomado, porém, em 1964, tem-se o golpe militar e implanta-se a ditadura no Brasil (até 1985), sob a lógica de uma anti-cidadania, ou, como caracterizou Santos (1979, p. 76), "cidadania em recesso", que suspendeu a participação popular do espaço governamental. Durante tais governos, a área social foi tratada de forma secundária, para não se dizer, terciária ou quaternária. No campo educacional o entrave aparece no que se refere à política educativa tecnicista, pouco apoiada pelos educadores brasileiros, além do compartilhamento da responsabilização da educação ao campo privado.

No contexto político entre esquerda e direita, nacionalistas versus entreguistas, no início dos anos 1960, após 13 anos de conflitos ideológicos e de lutas pela educação pública brasileira, foi aprovada a primeira Lei de Diretrizes e Bases da Educação (Lei n. 4.024, de 1961)que incorporou os princípios do direito à educação, da obrigatoriedade escolar e da extensão da escolaridade obrigatória nos seguintes termos: "A educação é direito de todos e será dada no lar e na escola" (Artigo $2^{\circ}$ ); "O direito à educação é assegurado pela obrigação do poder público e pela liberdade de iniciativa particular de ministrarem o ensino em todos os graus, na forma da lei" (Artigo $3^{\circ}$ ). (ROMANELLI, 1986, p. 176)

A partir de 1964, até 1985, o país viveu a "filantropia de clientela e apadrinhamento" (MESTRINER, 2005), sob o contexto da suspensão dos direitos políticos ordenados pelo governo militar. Ernesto Geisel (presidente do Brasil de 1974 a 1979) criou em 1974, o Ministério da Previdência e Assistência (MPAS) para uma atuação a favor da redução da pobreza, que atingia cerca de metade da população brasileira. Em relação à parceria do Estado com o setor privado assistencial, o governo militar ampliou o sistema de convênios, incentivando ainda mais a expansão dessas instituições que desenvolviam programas sociais.

A educação no período militar acentuou o aparelho ideológico do Estado, expandindo o ensino, porém com especificidades associadas à sua qualidade. Materiais didáticos foram adotadas para todo o território nacional, houve supressão 

1968 os militares implantaram o Al-5 que representou a ditadura com "D" maiúsculo.

Isso fica muito evidente na área da educação, um dos setores mais visados e mais atingidos pela repressão política pós-1964, porque diz respeito à formação das almas. Universidades foram invadidas por forças militares, a exemplo da Universidade de Brasília (UnB) - algumas tiveram reitores/ interventores militares -, e a União Nacional de Estudantes (UNE), logo após o golpe de Estado, teve a sua sede incendiada no Rio de Janeiro. Desse modo, muitos estudantes, professores e cientistas proeminentes, a exemplo de Paulo Freire, Celso Furtado, Florestan Fernandes, Darcy Ribeiro, Leite Lopes, Mário Schemberg e tantos outros foram processados, presos, cassados, exilados e assim por diante. Até mesmo uma polícia política universitária foi criada com o nome de Assessoria de Segurança e Informações (ASI). As palavras do Coronel Darcy Lázaro, comandante da primeira invasão da UnB, em 1964, diz bem desse desprezo pelo outro e pela cultura, uma vez que a cultura é o campo das diferenças: "Se essa história de cultura vai-nos atrapalhar a endireitar o Brasil, vamos acabar com a cultura durante trinta anos" (apud Germano, 1989, p. 21). Nada mais óbvio de que essa ojeriza à alteridade para esconder o desejo de eliminar o outro, de retirar os opositores da cena política, estabelecendo a ordem, tornando viável o progresso, conforme a visão autoritária. (GERMANO, 2008, p. 322)

Ao mesmo tempo, o governo militar adota o ensino profissionalizante, oferecendo a escola que educa para o trabalho. Em parte, esta concepção viria ao encontro do propósito de atender às necessidades de atendimento do modelo de expansão industrial que caracterizaria ao período do "Milagre Brasileiro4".

Tomando por base a composição clássica da cidadania, ao fazer um balanço da sua condição ao longo dos anos, é possível observar que de 1930 a 1945 viveu-se a era dos direitos sociais no Brasil (com restrição dos direitos políticos e paternalismo social). De 1945 a 1964 presenciou-se a ampliação dos direitos políticos e a lentidão dos direitos sociais. Durante o governo Militar passou-se pela restrição de direitos civis e políticos com a ampliação dos direitos sociais. De 1974 a 1985 ocorreu a volta dos direitos civis e políticos. Essa trajetória mostra o quanto a cidadania é desafiante em solo brasileiro.

A partir de 1985, até 1993, segundo Mestriner (2005, p. 181), o Brasil viveu a versão vigiada da filantropia, com a volta da democracia e a promulgação da Constituição de 1988, que finalmente permitiu a criação da tão sonhada política de assistência social, a qual se posicionou ao lado das demais políticas públicas, não mais como uma política de controle de pobres, mas como uma política provedora de

4 Segundo Veloso, Villela e Giambiagi (2008), o Milagre Brasileiro ocorreu durante o período 1968-1973, em que o PIB brasileiro cresceu a uma taxa de cerca de 11,1\% a.a., enquanto no período 1964-1967 o crescimento havia sido de 4,2\% a.a. A característica notável do "milagre" é que, simultaneamente devido às taxas muito elevadas de crescimento econômico, o período 1968-1973 caracterizou-se por taxas de inflação declinantes e relativamente baixas para os padrões brasileiros e por superávits no balanço de pagamentos. 
direitos. Também foi a Constituição de 1988, que garantiu, no seu artigo 208 o ensino fundamental gratuito e de direito público.

Leis orgânicas foram elaboradas para definir os novos rumos nas áreas da previdência, da saúde e da criança e do adolescente. Dessa forma, conforme caracterizou Sposati (2002, p. 1), o Brasil viveu uma regulação social do tipo tardia. No entanto, a lógica neoliberal, fortalecida na época, reforçada pela corrupção política, atrapalhou as propostas de alavancagem da cidadania, ameaçando um sonho que mal tinha começadono campo social e educacional.

Valorizando as importações, Collor implantou o Estado Mínimo, ou seja, mais mínimo do que já era até então, sob a lógica da globalização. Foram quase três anos de reduções de gastos a partir da venda dos bens públicos e redução de funcionários. Consequentemente ao caos instalado, a assistência social fatalmente retrocedeu à sua forma paternalista, representando mais uma frustração.

De 1994 até 2000, o Brasil teve mais uma versão filantrópica, a chamada filantropia democratizada representada pelo Conselho Nacional de Assistência Social (CNAS). Em 1995, criou-se a Secretaria Nacional de Assistência Social (SAS) em lugar da LBA e do Ministério de Bem-Estar Social. Novas discussões sobre a condição da assistência social no país foram colocadas em pauta, para se pensar na sua ressignificação.

Finalmente, em 1998, o CNAS aprovou a Política Nacional de Assistência Social, valorizando o tratamento das condições de pobreza e vulnerabilidade social no país, articulando ações e projetos a serem trabalhados pela esfera pública e privada no âmbito das famílias em situação de exclusão, com prioridade para a questão da infância e da adolescência. O trabalho foi focado e direcionado aos mais pobres dos pobres, isto é, aos moradores de rua, pessoas abaixo da linha de pobreza (fato que demonstrou a dificuldade de universalização dos direitos sociais no país).

Aprovou-se, a Norma Operacional Básica de Assistência Social, em 1999 (NOB 2), possibilitando a descentralização e a participação dos âmbitos municipais e estaduais no que se refere aos recursos para financiamento da assistência social, ou seja, municípios habilitados a gerir a assistência social no seu local receberiam financiamento direto da União, caso contrário, esse valor seria então repassado ao Estado. No aspecto da educação com o governo Fernando Henrique Cardoso, implantou-se o estado neoliberal na educação, ocorrendo o aumento das matrículas na escola pública no Brasil, mas houve, no campo da educação superior, a redução do papel do Estado com o consequente avanço da privatização das universidades. Em linhas, o que se verificou foi um enxugamento do Estado e um aumento da participação da iniciativa privada e a Educação foi bastante afetada. Além do movimento expansionista identificado no Ensino Superior, consolidou-se uma intensa 
ampliação da Educação Básica marcada pela concessão e por configurações de parcerias. O fato é que esta ampliação impactou de forma significativa não somente as dimensões espaciais das escolas e seu formato de gestão, mas atingiria também as propostas pedagógicas (conf. SANTOS, MARTINS \& GIMENEZ, 2019). Em parte, uma das consequências disto seria contatada por meio da ampliação de Escolas de Educação Infantil, funcionando em espaços limitados e com configurações não recomendadas para as crianças e por uma franca expansão de sistemas de Ensino orientados ao Ensino Fundamental, adotados sobretudo por instituições privadas de médio porte.

No início do presente século, o país avançou na política de assistência social com a criação do Sistema Único de Assistência Social (SUAS) em 2005, a partir da Norma Operacional Básica NOB/SUAS, que se constituiu a partir de um conjunto de serviços, projetos, programas e benefícios socioassistenciais organizados a partir da lógica pública da proteção social governamental, e em parceria comas organizações da sociedade civil. O SUAS estabeleceu a presença estatal com os Centros de Referências de Assistência Social (CRAS) e com os Centros de Referências Especial de Assistência Social (CREAS), que têm por responsabilidade organizar e coordenar o trabalho de assistência social em cada município do país.

Yazbek (1995) denomina o processo cíclico, de volta à filantropia, como sendo a refilantropização da questão social, ou seja, embora se avance no processo político da assistência social, a tendência à benemerência, ao assistencialismo, ao voluntariado, se faz presente, retomando antigas práticas. No que se refere ao sistema educacional, conforme Bittar e Bittar (2012), "foi mais fácil expandir o sistema do que fazê-lo cumprir sua função de promover aprendizagem às crianças e aos jovens brasileiros. Nesse início do século XXI, é possível afirmar que o Brasil tem escolas, mas o problema é que elas são precárias". Dessa forma, a educação brasileira ensaiou avanços, mas permaneceu no campo da manutenção do subjugo dos indivíduos mediante um sistema manipulador, longe de ser democrático e equalitário. Mais uma vez temos a faça exclusória sob o aspecto dos direitos sociais subtraídos e limitados.

\section{CONSIDERAÇÕES FINAIS}

O presente artigo apresentou como se deu o enfrentamento da questão social sob as faces da filantropia e da cidadania, observando que, conforme Castel (1998), os pobres sofreram severamente, ao longo dos séculos, com a desfiliação social permitida pelas lacunas de proteção, seja ela próxima, secundária ou do próprio Estado. Diversas formas de seguro social se fizeram presentes tanto em sociedades europeias como nas latinas, como a brasileira, porém sem oferecer efetivamente um 
Estado protetivo efetivo e permanente aos seus cidadãos. Ainda que se considere as particularidades do campo educacional, da mesma forma, os pobres não eram alvo do interesse educativo, já que a formação era encaminhada, sobretudo, junto aos filhos das camadas abastadas da sociedade, os quais futuramente assumiriam a gestão da nação ou as posições de destaque.

O Brasil enfrentou a pobreza sob o tratamento da filantropia, desde a sua colonização, tendo as Igrejas, em especial as católicas, como centro dessa atuação. A Igreja Protestante, buscando posicionar-se frente aos desafios de tal pobreza também partilhou da atuação filantrópica. Particularmente, em relação ao ensino as instituições religiosas também tiveram presença pioneira, mantendo o ensino e a formação vinculados ao espaço teológico.

Neste sentido, não haveria distinção entre o eclesiástico, o social e o educacional, porém, existiria uma opção, defendida pela liderança da Igreja, de não institucionalização do trabalho social e de ensino. A Igreja prefere manter suas iniciativas sociais no campo privado do voluntariado social e no caso do ensino, no campo privado remunerado. Também é possível observar que ocorre uma tendência de atuação que segue a lógica histórica do tratamento da pobreza a partir de uma percepção focada no necessitado e menos na necessidade, recaindo na individualização do fenômeno social. Portanto, as análises bibliográficas, demonstram que a raiz histórica brasileira das práticas socioassistenciais sob o signo da ajuda individualizada perpassa todos os setores da sociedade (a qual inclui o próprio Estado), não conferindo diretamente a condição de direito ao cidadão. Da mesma forma, o tratamento da educação carrega a sua origem opressiva de subjugo ao indivíduo empobrecido, oferecendo limitadamente o espaço formativo às elites. Tal fato dificulta o transito do paradigma do favor para o paradigma do direito no campo socioassistencial e educacional.

Parece haver uma confusão entre Estado e governo, fato esse de raiz protestante, a qual entende que o público é sinônimo de governamental e não uma responsabilidade de todos. Nesse cenário, as ações no campo social se realizam de forma isolada e não se encontram em sintonia com as diretrizes das políticas sociais públicas distanciando-se da perspectiva mais estruturante de contribuição à redução da desigualdade social.

Nessa direção observa-se que há uma regulamentação estatal dos serviços socioassistenciais no Brasil, desde a instalação do SUAS, mas não há regulação da processualidade dos direitos, a partir dos serviços prestados (de forma direta ou indireta pelo Estado), o que tem gerado um impasse no campo da política pública de assistência social. As políticas educacionais também foram regulamentadas pelo Estado brasileiro, mas o alcance dos direitos educativos encontra desafios severos para se efetivarem. 
Dessa forma, se reconhece o direito no campo privado, civil, político, mas há mais dificuldade quanto ao seu alcance no âmbito público. É preciso que os serviços sociais prestados pelas organizações privadas integrem e fortaleçam tanto a rede de proteção social pública como a rede de ensino público. Não se trata de substituir o papel social que pertence ao Estado, mas de manter parceria nessa responsabilidade, fortalecendo sua presença na sociedade, enquanto mediação necessária à garantia dos direitos sociais a todos os cidadãos.

\section{REFERÊNCIAS}

ABREU, S. A.; CASTRO, M. M.A pobreza colonizada. Revista Serviço Social e Sociedade, São Paulo, v.4, n.17, 1985, p. 49-72,

BITTAR, M; BITTAR, M. História da educação no Brasil: a escola pública no processo de democratização da sociedade. Revista Acta Scientiarum Education, Maringá, v. 34, n. 2, 2012, p. 157-168, Disponível em: http://periodicos.uem.br/ojs/index.php/ ActaSciEduc/article/view/17497

CARVALHO, J. M. Cidadania no Brasil: o longo caminho. 5.ed. Rio de Janeiro: Civilização Brasileira, 2004.

CASTEL, R. As metamorfoses da questão social: uma crítica do salário. Rio de Janeiro: Vozes, 1998.

DANTAS, M. Informação e trabalho no capitalismo contemporâneo. Revista Lua Nova, n. 60, 2003, p. 13-14 Disponível em: http://www.scielo.br/pdf/ln/n60/a02n60.pdf

FARIA, C. A. P. Uma genealogia das teorias e modelos do estado de bem-estar social. Revista Brasileira de Informação Bibliográfica em Ciências Sociais, Rio de Janeiro, n.46, 1998, p. 39-52

GERMANO, J. W. O discurso político sobre a educação no Brasil autoritário. Caderno Cedes, Campinas, v. 28, n. 76, 2008, p. 313-332

GRELLERT, M. Os compromissos da missão: caminhada da lgreja no contexto brasileiro. Rio de Janeiro: Juerp, 1987.

LANDIM, L. Para além do mercado e do estado? Filantropia e cidadania no Brasil. Rio de Janeiro: ISER, 1993.

MACEDO, R. M. S.; MARTINS, S. R. C. Conceitos de infância e leis que protegem crianças e adolescentes. In: COSTA, L. F.; PENSO,M. A.; CONCEIÇÃO, M. I. G. (org.) Abordagem à família no contexto do conselho tutelar. São Paulo: Ágora, 2014. 
MARSHALL, T. H. Cidadania, classe social e status. Rio de Janeiro: Zahar, 1967.

MESTRINER, M. L. O Estado entre a filantropia e a assistência social. 2.ed.São Paulo: Cortez, 2005.

PACE, ENZO. Religion as communication: the changing shape of Catholicism in Europe. In: Ammerman, N.T. Everyday religion: observing modern religion lives. Oxford, Oxford University Press, 2007. (p.37-50).

PADILLA, R. C. Missão integral: ensaios sobre o reino e a igreja. 2.ed. Londrina: Descoberta, 2005.

PASCQUALOTTO, LUCYELLE CRISTINA. Revista Faz Ciência, v.8, n.1, 2006, p.325, 342

PERNOUD, R. Luz sobre a Idade Média. Portugal: Publicações Europa-améi, 1997 REILY, LÚCIA. O papel da igreja nos primórdios da educação dos surdos. Revista Brasileira de Educação, v.12, n.35, p.308-326. https://doi.org/10.1590/S141324782007000200011

ROMANELLI, O. O. História da Educação no Brasil (1930/1973). 8. ed. Petrópolis: Vozes, 1986.

ROMANO, R. Brasil: igreja contra estado. São Paulo: Kairós, 1979.

SANTOS, M.P. A Pedagogia filosófica do movimento iluminista no século XVIII e suas repercussões na educação escolar contemporânea: uma abordagem histórica. Revista Imagens da Educação, Paraná, v.3, n. 2, 2013, p. 1-13, Disponível em: http://periodicos.uem.br/ojs/index.php/ImagensEduc/article/view/19881

SANTOS, W. G. Cidadania e justiça: a política social na ordem brasileira. Rio de Janeiro: Campus, 1979.

SANTOS, F. X.; MARTINS, I. C.; GIMENEZ, R. O brincar e os contextos físicos escolares: uma reflexão sobre a educação infantil no Município de São Paulo. Revista @mbienteeducação, v. 12, 2019, p. 177-201

SAVIANI, D. Vicissitudes e perspectivas do direito à educação no Brasil: abordagem histórica e situação atual. Revista Educação e Sociedade, Campinas,v.34 n. 124 , p. 746. Disponível em: http://www.scielo.br/scielo.php?pid=s010173302013000300006\&script=sci_abstract\&tlng=pt 
SPOSATI, A. Regulação social tardia: característica das políticas sociais latinoamericanas na passagem entre o segundo e o terceiro milênio. In: CONGRESSO INTERNACIONAL DEL CLAD, 7., 2002, Lisboa. Anais eletrônicos[...].Lisboa, 2002. Disponivel em :http://www1.londrina.pr.gov.br/dados/images/stories/Storage/sec_ assistencia/pdf/Regulacao_social_tardia_Aldaisa.pdf

SOUZA, P. R.; FERREIRA, M. M. M.; BARROS, M. S. F. História da criação da escola pública como instrumento da formação da educação burguesa. In: CONGRESSO NACIONAL DE EDUCAÇÃO - EDUCERE III ENCONTRO SUL BRASILEIRO DE PSICOPEDAGOGIA. Disponível em: https://educere.bruc.com.br/ arquivo/pdf2009/2475_1142.pdf

STEUERNAGEL, V. R. A cisão da igreja: uma visão panorâmica sobre os desafios e propostas de missão para a igreja na antevéspera do terceiro milênio. Belo Horizonte: Missão Editora, 1994.

STOTT, J. R. W. Evangelização e responsabilidade social. 2.ed. Belo Horizonte: Visão Mundial, 2004.

STOTT, J. R. W. A missão cristã no mundo. São Paulo: Candeia, 2008.

TELLES, V. S. Pobreza e cidadania. São Paulo: Editora 34, 2001.

VELOSO, F. A.; VILLELA, A.; GIAMBIAGI, F. Determinantes do "milagre" econômico brasileiro (1968-1973): uma análise empírica. Revista Brasileira de Economia, v. 62, n. 2, 2008. Disponível em: http://www.scielo.br/pdf/rbe/v62n2/06.pdf

VISÃO MUNDIAL. Recuperado de: https://visaomundial.org/

YAZBEK, M. C. A. Política social brasileira dos anos 90: a refilantropização da questão social. Cadernos ABONG, Série Especial, Subsídios Conferência Nacional de Assistência Social, n.3,1995.

\section{SOBRE OS AUTORES}

VIVIANE SPARADARO DI GESÚ. Doutoranda em Educação pela Universidade Cidade de São Paulo. Mestre em Políticas Sociais pela Universidade Cruzeiro do Sul. Coordenadora dos cursos de Cursos Superiores de Tecnologia da Cruzeiro do Sul Educacional e de Pós-Graduação em Comunicação e Marketing da Cruzeiro do Sul Educacional. Instituição: Universidade Cruzeiro do Sul. 
DIRCE HARUE UENO. Doutora em Serviço Social pela PUC-SP. Instituição: Programa de Estudos Pós-Graduados em Serviço Social - PUC-SP.

ROBERTO GIMENEZ. Doutor em Educação Física pela Universidade de São Paulo (USP). Pesquisador do Programa de Mestrado e Doutorado em Educação da Universidade Cidade de São Paulo e do Programa de Formação de Gestores Educacionais da Universidade Cidade de São Paulo. Coordenador do curso de Educação Física da Universidade Cidade de São Paulo. Professor da Universidade Nove de Julho. Instituição: Universidade Cidade de São Paulo.

RECEBIDO: 28/04/2020.

APROVADO: 06/05/2020. 